\title{
Performance Analysis of a Low Head Water Vortex Turbine
}

\author{
Badhan Saha1*, Mazharul Islam², Khondoker Nimul Islam³, Jubair Naim', and MD Shahriar Farabi ${ }^{5}$ \\ Department of Mechanical and Production Engineering (MPE), Ahsanullah University of Science and Technology (AUST), Dhaka, \\ Bangladesh \\ emails: ${ }^{*}$ badhan.mpe@aust.edu;2mazharul.islam.mpe@aust.edu; ${ }^{3}$ foysalkhondoker@gmail.com; \\ 4jubairnaimakash9854@gmail.com; and ${ }^{5}$ shahriarfarabiw30@gmail.com
}

\section{ART I CLE I N F O \\ Article History: \\ Received: 04th May 2021 \\ Revised: $18^{\text {th }}$ November 2021 \\ Accepted: 20 ${ }^{\text {th }}$ November 2021 \\ Published: 23rd December 2021}

\section{Keywords:}

Water vortex turbine

Micro hydro power

Renewable energy

\begin{abstract}
A B S T RACT
A small hydropower plant is an environment-friendly renewable energy technology. The run-of-river type gravitational water vortex turbine can be designed to produce electricity at sites with low water heads. In this study, an experimental investigation was undertaken on this type of turbine with a water tank and a runner which is connected to a shaft. At the end of the shaft, a rope brake was attached to measure the output power, torque and overall efficiency of the vortex turbine by varying flow rates. The designed vortex turbine can achieve an overall efficiency of $52.67 \%$. The experimental results were validated with available data in the literature and theories associated with the turbine. The results also showed that the flow rate plays a vital role in generating power, torque as well as overall efficiency. The project was completed using local resources and technologies. Moreover, as water is used as the input power, this project is eco-friendly which has no adverse effect on the environment.
\end{abstract}

(C) 2021 MIJST. All rights reserved.

\section{INTRODUCTION}

A micro-hydropower plant like a low head gravitational water vortex power generation system can be installed in prospective sites to generate pollution-free electricity. The water vortex turbine, as shown in Figure 1, is a simply constructed turbine that can produce electricity using water flows. The turbine is placed into a conical basin where the vortex is generated. When water is introduced into a conical basin tangentially, it creates a vortex and energy is harnessed. The blades of the turbine can be straight or curved. A dynamo can be coupled with the shaft of the turbine to produce electricity.

A two-dimensional representation of the experimental setup of the vortex turbine has been shown in Figure 2. In Figure 2 (a), various parts have been incorporated and in Figure 2 (b), the dimensions of various parts of the vortex turbine have been presented. Figure 3 shows the threedimensional CAD drawing and Figure 4 shows the actual experimental setup of the vortex turbine with various parts.

Austrian engineer Frank Zotloterer invented different types" of Gravitational Water Vortex Power Plant (GWVPP) which has the potential to generate power using low head (ZOTLÖTERER, 2011). According to (Ersoy, 2014), Hakim investigated the effect of distances between oscillating parts in a vortex-induced power generation. Permana (Permana, 2011) studied the effect of the free surface on the oscillating part involving the performance of a vortex turbine. He found that the lower the location of the oscillating part, the greater the amplitude of the water level and vice versa. This finding is due to many reasons and one of which is the holder stability.

Bernitsas and Raghavan (Bernitsas et al., 2006) designed a vortex-induced vibration aquatic clean energy (VIVACE) converter which used ocean/river current hydrokinetic energy for the first time. Punit Singh and Franz Nestmann (Singh \& Nestmann, 2009) designed an optimized waterfree vortex propeller runner for micro-hydro application and conducted experimental investigations.

Piyawat Sritram and Ratchaphon Suntivarakorn (Sritram \& Suntivarakorn, 2017) showed a comparison between the water-free vortex turbine and the small undershot water turbine. They (Sritram \& Suntivarakorn, 2017) found that the highest efficiency of a waterfree vortex turbine was $35.92 \%$ at the rotational speed of $50 \mathrm{rpm}$ and the torque was $2.77 \mathrm{~N}-\mathrm{m}$. The output power of their turbine was 14.5 W.

Recently an experimental investigation has been carried out by Saleem et al. (A.S. Saleem et al., 2020) to investigate the various performance parameters of gravitational water vortex turbine (GWVT) by varying design and flow conditions. They have shown that to get better performance from (GWVT), the vortex height and vortex shape have been played an important role. They have also suggested that the better performance of the 
GWVT can be found at the middle range of rotational speed. They have found that the multistage GWVT has produced more power than single-stage GWVT. Rahman et al. (Rahman et al., 2018) have performed an experimental investigation Ullah et al. (Ullah et al. 2020) have performed an experimental investigation on multistage GWVT using savonius type blades and telescopic shafts to investigate the effects of various parameters on the performance of GWVTto study the effects of inlet flow rates on the performance of GWVT. They have shown that the efficiency of the GWVT has been increased when the inlet flow rate has become higher. Moreover, they have found greater efficiency as well as power with large deflector length and small penstock's feeding width. Bajracharya et al. (2020) have performed numerical and experimental investigations to reveal the effects of geometrical parameters on the performance of GWVT. From their experimental and numerical analysis, they have suggested that when designing a turbine runner, the height of the runner should be considered as the most significant parameter.

In the present research, the main focus was to fabricate a small-scale vortex turbine and to test the performance at different operating conditions.

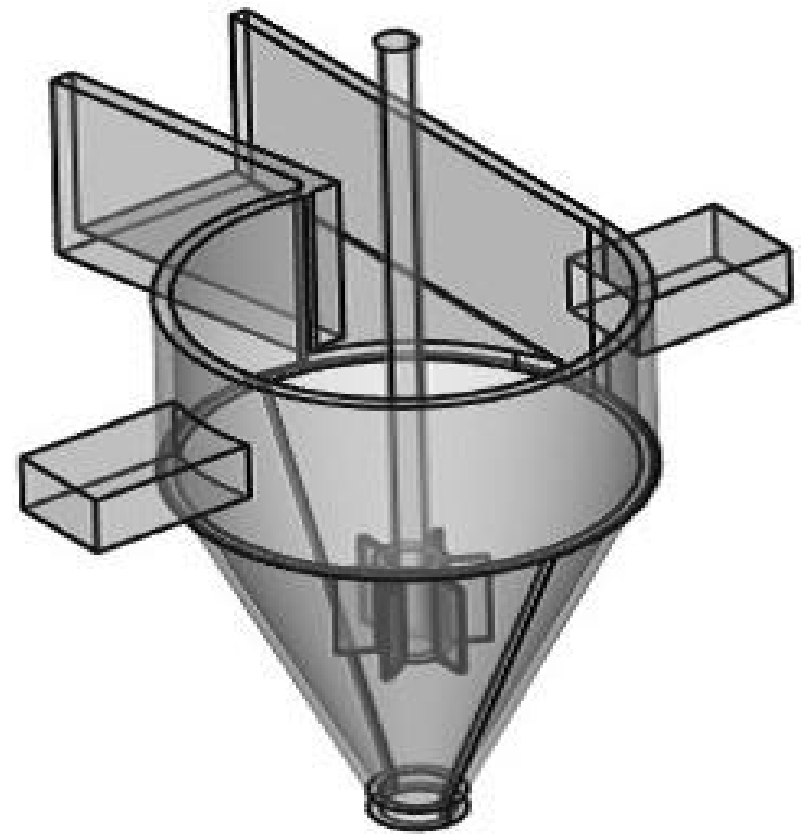

Figure 1: Illustration of a Gravitational Water Vortex Turbine inside a Conical Chamber

\section{MATERIALS AND METHODS}

\section{A. Main Components}

An experimental setup was prepared for laboratory investigation using a vortex turbine, as shown in Figure 5. The main components of the experimental setup were:

- A water tank to supply water to the turbine

- A canal with a notch to increase the water velocity

- A conical basin to generate vortex

- A straight bladed vortex turbine with six blades with a diameter of $0.11 \mathrm{~m}$ to generate torque
- A centrifugal pump to return the water from the water tank to the canal

- A rope-brake dynamometer mechanism (GUPTA, 2012) to measure torque generated by the turbine

- A digital tachometer to measure the turbine rotational speed

The salient parameters of the experimental setup are illustrated in Figure 2 and a 3D representation of the setup is shown in Figure 3. The basin height of the setup is 0.375 $\mathrm{m}$ with an inlet diameter of $0.400 \mathrm{~m}$ and an outlet diameter of $0.0816 \mathrm{~m}$. The canal height of the setup is $0.2 \mathrm{~m}$ and the total length is $1.47 \mathrm{~m}$. The Notch Angle, shown in Figure 2 , of the turbine, is 15 degrees and the cone angle, also shown in Figure 2, is 67 degrees. There were different types and angles of blade arrangements attached with the turbine. In this experiment straight bladed water vortex turbine was used that had six blades with a diameter of $0.11 \mathrm{~m}$.

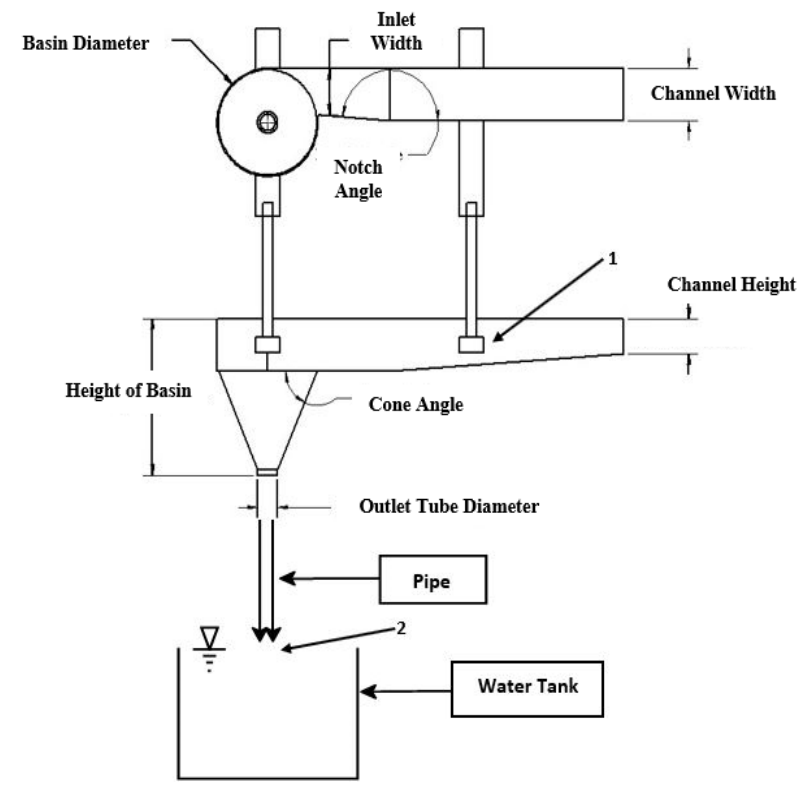

(a)

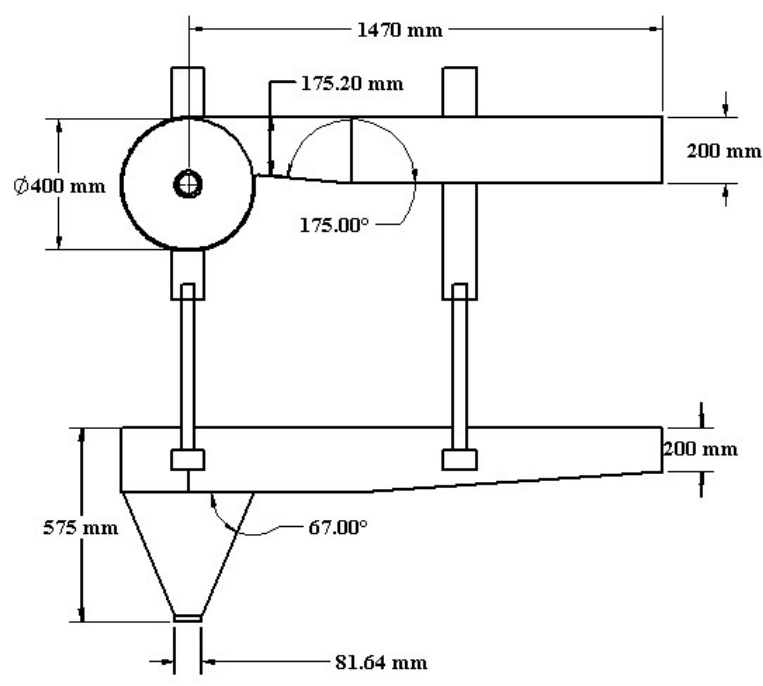

(b)

Figure 2: Experimental Setup in 2D with (a) various parts and (b) dimensions 


\section{B. Procedures}

The experimental procedure is shown in Figure 5. Initially, water was fed from the water tank (shown in Figures 2 and 5) to the canal. The water flow was controlled by a ball valve, attached to the pressure gauge, manually. Then, the water was flowing through the flow meter and was delivered to the conical basin.

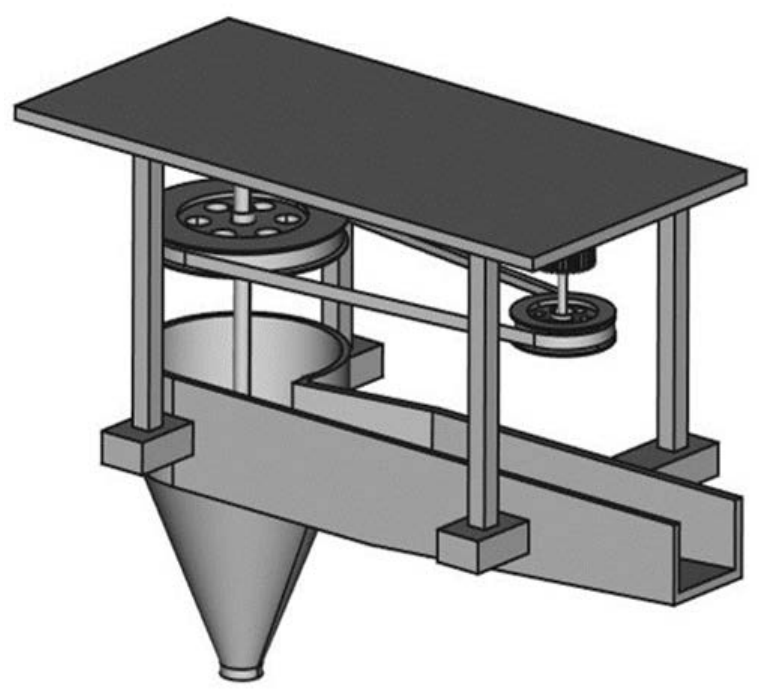

Figure 3: The Experimental Setup in 3D

In the conical basin, a vortex was generated due to its shape. This vortex impinged on the vortex turbine blades to generate the desired torque. One of the ends of the shaft was attached to the turbine and the other end was attached to a rope brake dynamometer. In the research, the flow rates of incoming water were varied between 0.000859 $\mathrm{m}^{3} / \mathrm{s}$ to $0.00172 \mathrm{~m}^{3} / \mathrm{s}$. The variations of pressures were between 8618.45 and $89631.8 \mathrm{~Pa}$.

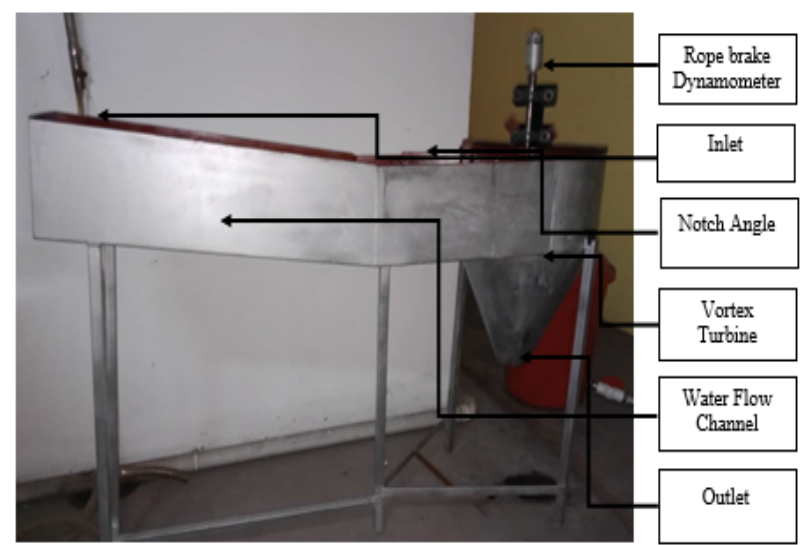

Figure 4: Picture of the Experimental Setup

The torque generated by the vortex turbine was measured by using a rope-brake system shown in Figure 6. The load was increased in the rope brake dynamometer to reduce the turbine rotation by adjusting the tension of the spring balances. The measured value of the highest rpm was 264 at 89631.8 Pa and the lowest rpm was 98 at $8618.45 \mathrm{~Pa}$.

As this is a small scale project, the water pressure was confined to $89631.8 \mathrm{~Pa}$, but on a larger scale project, it can be increased along with the flow rate. It was observed that the rpm increased with the increase of the water flow rates. The whole experiment was repeated by varying the flow rates and the data were measured several times to decrease uncertainties.

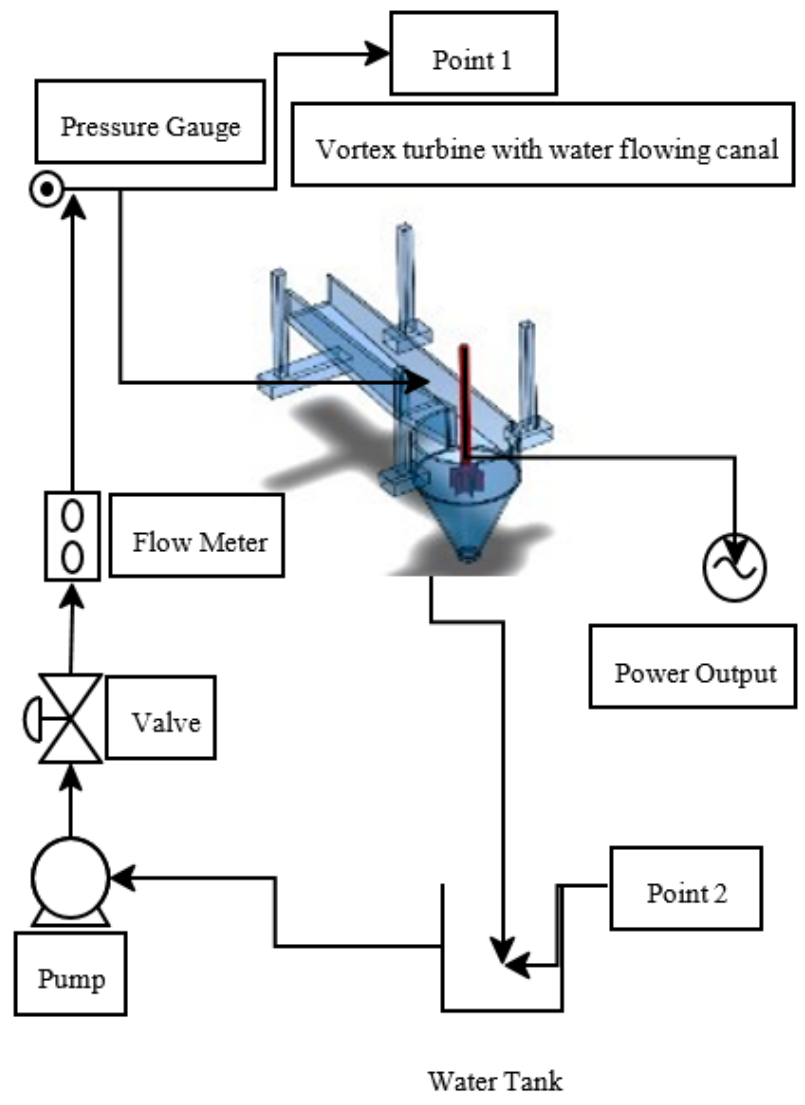

Figure 5: Methodology of the Experimental Investigation

\section{MATHMETICAL EXPRESSION}

\section{A. Turbine Head}

Applying Mechanical Energy Equation between points 1 and 2, as shown in Figure 5, we get (Çengel, Y., \& Cimbala, J, 2014)

$\frac{p_{1}}{\rho g}+\frac{v^{2} 1}{2 g}+z_{1}-h_{T}=\frac{p_{2}}{\rho g}+\frac{v^{2} 2}{2 g}+z_{2}-h_{L}$

It should be noted that Pressure at points 1 (indicates the inlet) \& 2 (indicates the outlet) are basically atmospheric pressures. As $v_{2} \ll v_{1}, v_{2}$ can be neglected to simplify the equation. Also, the head loss term in the above equation (denoted by $h_{L}$ ) has also been neglected. Applying these assumptions, the above equation become.

$h_{T}(m)=\frac{v^{2} 1}{2 g}+\Delta Z$

\section{B. Flow Rate}

$Q=A v$

$v=\frac{Q}{A}=\frac{4 Q}{\pi d^{2}}$

\section{Hydro Power}

The hydropower available in the inlet of the vortex turbine (indicated by $P_{i}$ ) can be determined from (Çengel, Y., \& Cimbala, J, 2014)

$P i=\gamma Q h_{T} \quad\lfloor W\rfloor$ 


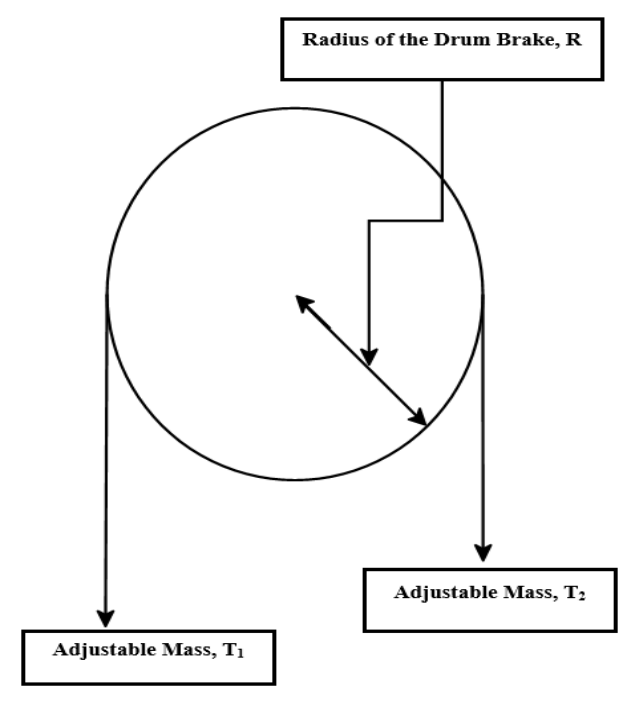

Figure 6: Schematic Representation of the Rope Brake Dynamometer

\section{Output Power}

The power generated from the vortex turbine (indicated by $P_{o}$ ) can be determined from the following expression obtained from (GUPTA, 2012)

$P o=\left(T_{1}-T_{2}\right) g \omega R \quad\lfloor W\rfloor$

Overall Efficiency $(\eta)$ can be expressed by

$\eta=\frac{P o}{P i} \times 100$

\section{RESULTS AND DISCUSSION}

\section{A. Variation of Rotational Speed with Flow Rate}

Based on the experimental investigation mentioned earlier, variation of flow rate with the turbine rotational speed is plotted and shown in Figure 7. From this figure, it was observed that with the increase of the flow rate, the rotational speed increased. It occurs because of gradual increase in the volume of water creates more pressure on the turbine blade. Hence the turbine rotates at a greater speed. The highest rotational speed in rpm was 264 at a flow rate of $0.00172 \mathrm{~m}^{3} / \mathrm{s}$. It should be noted that Sritram and Suntivarakorn (2017) obtained a similar trend and they showed that the rotational speed of a water vortex turbine increased with the increase of flow rates.

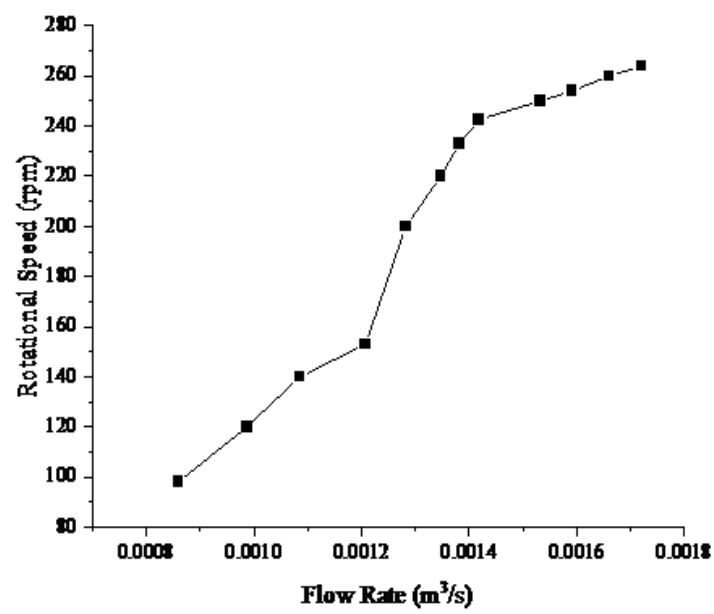

Figure 7: Variation of Flow Rates with Rotational Speed

\section{B. Variation of Efficiency with Rotational Speed}

Figure 8 shows the variation of efficiency with rotational speed. As the flow rate increases, the rotational speed and the corresponding efficiency of the water vortex turbine also increases. At the flow rate of $0.00172 \mathrm{~m}^{3} / \mathrm{s}$ corresponding pressure was $89631.8 \mathrm{~Pa}$. In that time the highest magnitude of efficiency has been found. The magnitude of the highest efficiency was 52.67\% (at 264 $\mathrm{rpm}$ ) and the lowest efficiency was 2.22\% (at $98 \mathrm{rpm}$ ). Dhakal et al. (2017) showed the rpm versus efficiency curve in their experimental work, which is quite similar to the curve obtained in the present work.

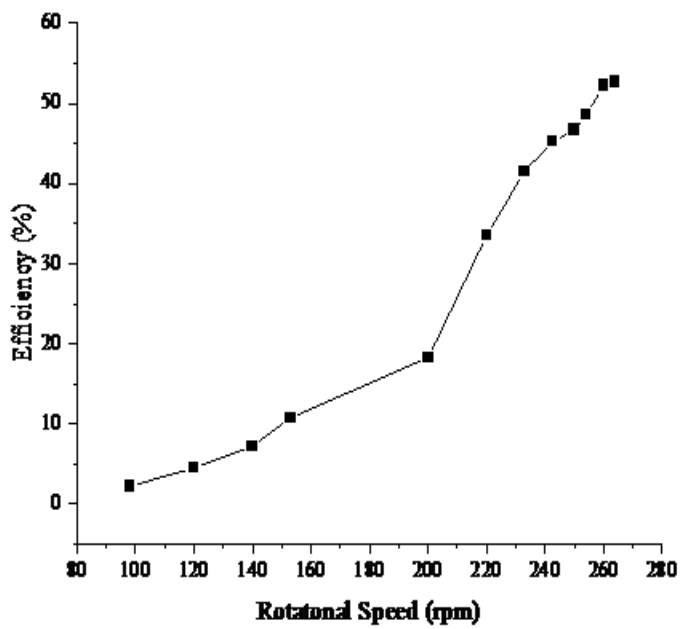

Figure 8: Variation of Efficiency with Rotational Speed

\section{Variation of Rotational Speed with Flow Rate}

Figure 9 shows the variation of output power with rotational speed. From this figure, it was observed that with the increase of the rotational speed, the output power also increased. This is due to the fact that as the rotational speed of the flow rate of $0.00172 \mathrm{~m}^{3} / \mathrm{s}$ and pressure of 89631.8 $\mathrm{Pa}$, the highest amount of output power (which was $12.3 \mathrm{~W}$ ) was obtained at the rotational speed of 264 rpm. The lowest output power was $0.177 \mathrm{~W}$ at a rotational speed of $98 \mathrm{rpm}$.

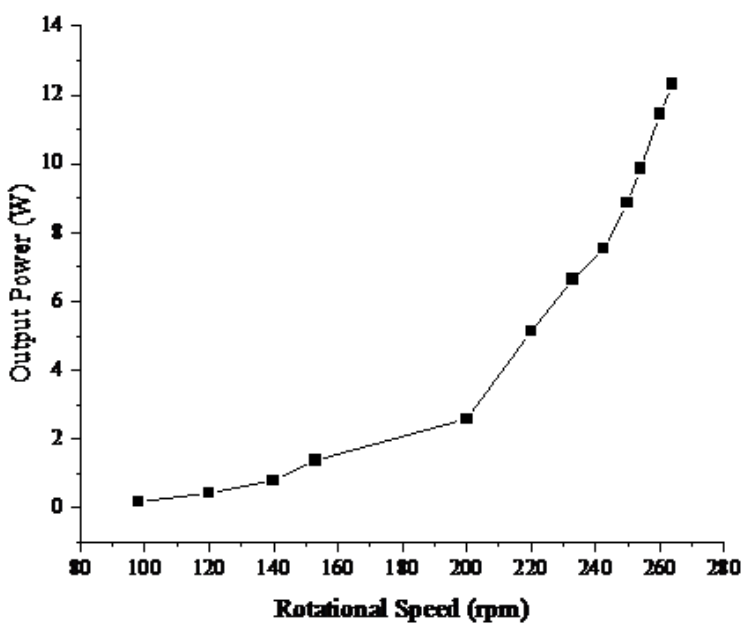

Figure 9: Variation of Power Output with Rotational Speed

\section{Variation of Torque with Flow Rate}

The variations of torque with flow rates are shown in Figure 
10. It is seen that the torque increased with the increase of flow rate. As the flow rate increased, the corresponding volume of water is also increased. Different amounts of masses were applied to reduce the rpm and the corresponding magnitude of torque was recorded along with the rotational speed in rpm and flow rate. The maximum torque was $0.44538 \mathrm{~N}-\mathrm{m}$ at a flow rate of $0.00172 \mathrm{~m}^{3} / \mathrm{s}$. The lowest torque was $0.0172 \mathrm{~N}-\mathrm{m}$ at a flow rate of $0.000859 \mathrm{~m}^{3} / \mathrm{s}$.

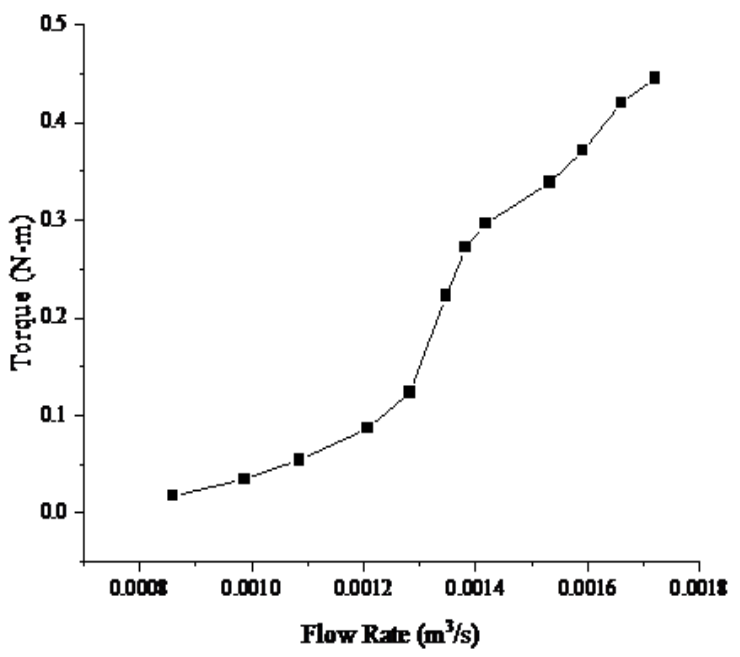

Figure 10: Variation of Torque with Flow Rates

\section{CONCLUSIONS}

A small-scale water vortex turbine with straight blades has been fabricated with the locally available materials and manufacturing facility in Dhaka for conducting experimental investigations. Experimental works were conducted with several important parameters related to the performance of a vortex turbine. It was found that as the flow rate increase, the rpm, output power and efficiency also increase. The generated output power was $12.3 \mathrm{~W}$ at a rotational speed of $264 \mathrm{rpm}$ and the resulting efficiency was $52.67 \%$. In future, a vortex turbine with curved blades may be investigated for higher efficiency.

\section{NOMENCLATURE}

$\mathrm{D}$

$E_{t}$

$\mathrm{N}$

$p_{1}$

$p_{2}$

$Q$

$R$

$v_{1}$

$v_{1}$

$T_{1}$

$T_{2}$

$Z_{1}$

$Z_{2}$

GWVPP Gravitational Water Vortex Power Plant

VIVACE Vortex-Induced Vibration Aquatic Clean Energy

VIV Vortex-Induced Vibration

$\omega \quad$ Rotational speed in $\mathrm{rad} / \mathrm{s}=\frac{2 \pi N}{\mathbf{6 0}}$

\section{ACKNOWLEDGMENTS}

The authors are grateful to the Department of Mechanical and Production Engineering, Ahsanullah University of Science, and Technology (AUST) for the overall supports to carry out this project. A special thank goes to those who helped to complete this project.

\section{REFERENCES}

Alwan, H., \& Al-Mohammed, F. (2018). Discharge coefficient for rectangular notch using a dimensional analysis technique. IOP Conference Series: Materials Science And Engineering, 433, 012015. https://doi.org/10.1088/1757899x/433/1/012015

Bajracharya, T. R., Shakya, S. R., Timilsina, A. B., Dhakal, J., Neupane, S., Gautam, A., \& Sapkota, A. (2020). Effects of Geometrical Parameters in Gravitational Water Vortex Turbines with Conical Basin. Journal of Renewable Energy, 2020(Figure 1), 1-16. https://doi.org/10.1155/2020/5373784

Bernitsas, M. M., Raghavan, K., Ben-Simon, Y., \& Garcia, E. M. (2006). VIVACE (Vortex induced vibration aquatic clean energy): A new concept in generation of clean and renewable energy from fluid flow. Volume 2: Ocean Engineering and Polar and Arctic Sciences and Technology, 2. https://doi.org/10.1115/omae2006-92645

Butera, I., \& Balestra, R. (2015). Estimation of the hydropower potential of irrigation networks. Renewable And Sustainable Energy Reviews, 48, 140-151. https://doi.org/10.1016/j.rser.2015.03.046

Çengel, Y., \& Cimbala, J. Fluid mechanics (3rd ed., p. 971). McGraw-Hill Education.

Graebel, W. (2007). Advanced fluid mechanics (1st ed., p. 368). Academic Press.

GUPTA, H. N. (2012). Fundamentals of internal combustion engines (2nd ed.). PHI Learning Pvt.

Dhakal, R., Bajracharya, T., Shakya, S., Kumal, B., Khanal, K., \& Williamson, S. et al. (2017). Notice of Violation of IEEE Publication Principles: Computational and experimental investigation of runner for gravitational water vortex power plant. 2017 IEEE 6Th International Conference On Renewable Energy Research And Applications (ICRERA), 9. https://doi.org/10.1109/icrera.2017.8191087

Ersoy, S. (2014). Vortex with the Formation of Electricity Generation and System Modelling. International Journal Of Environmental Science And Development, 5(468), 152-154. https://doi.org/10.7763/ijesd.2014.v5.468

Huda, L. (2011). A study on the effect of dimensional oscillating part of vortex power plant using physical test [Master's thesis]. Department of Ocean Engineering Faculty of Marine Technology Institute Technology of Sepuluh.

Kaldellis, J. (2007). The contribution of small hydro power stations to the electricity generation in Greece: Technical and economic considerations. Energy Policy, 35(4), 21872196. https://doi.org/10.1016/j.enpol.2006.06.021

Khurmi, R. (1987). Textbook of Hydraulics, Fluid Mechanics and Hydraulic Machines (15th ed., p. 990). S Chand \& Co.

Permana, D. W. (2011). Study effect of free surface on the oscillating part concerning to the performance lies vortex power: physical test phenomenological [Master's thesis]. Department of Ocean Engineering Faculty of Marine Technology Institute Technology of Sepuluh.

Rahman, M. M., Hong, T. J., \& Tamiri, F. M. (2018). Effects of inlet flow rate and penstock's geometry on the performance of Gravitational Water Vortex Power Plant. Proceedings of the International Conference on Industrial Engineering and Operations Management, 2018-March, 2968-2976

Razan, J., Islam, R., Hasan, R., Hasan, S., \& Islam, F. (2012). A Comprehensive Study of Micro-Hydropower Plant and Its 
Potential in Bangladesh. ISRN Renewable Energy, 2012, 110. https://doi.org/10.5402/2012/635396

Saleem, A. S., Cheema, T. A., Ullah, R., Ahmad, S. M., Chattha, J. A., Akbar, B., \& Park, C. W. (2020). Parametric study of single-stage gravitational water vortex turbine with cylindrical basin. Energy, 200, 117464. https://doi.org/10.1016/j.energy.2020.117464

Singh, P., \& Nestmann, F. (2009). Experimental optimization of a free vortex propeller runner for micro hydro application. Experimental Thermal and Fluid Science, 33(6), 991-

1002. https://doi.org/10.1016/j.expthermflusci.2009.04.007

Sritram, P., \& Suntivarakorn, R. (2017). Comparative study of small hydropower turbine efficiency at low head water. Energy

Procedia, 138,646650. https://doi.org/10.1016/j.egypro.2017.10.181

Ullah, R., Cheema, T. A., Saleem, A. S., Ahmad, S. M., Chattha, J. A., \& Park, C. W. (2020). Preliminary experimental study on multi-stage gravitational water vortex turbine in a conical basin. Renewable Energy, 145, 2516-2529. https://doi.org/10.1016/j.renene.2019.07.128

White, F. (2011). Fluid mechanics (7th ed., p. 863). McGraw-Hill Education (India) Private Limited.

Yamaguchi, H. (2008). Engineering fluid mechanics (1st ed.). Springer.

Zotlöterer, F. (2011). Hydroelectric power plant. Germany. Patent No WO 2011051421A2. 